\title{
The Effect of Sprint Training on Vertical Jump Height of Female Youth Volleyball Players
}

\author{
Nur Cholis Majid", Fauzi \\ Department of Sport Science, Yogyakarta State University, Yogyakarta 55281, Indonesia
}

Received January 8, 2021; Revised February 20, 2021; Accepted March 23, 2021

\section{Cite This Paper in the following Citation Styles}

(a): [1] Nur Cholis Majid, Fauzi, "The Effect of Sprint Training on Vertical Jump Height of Female Youth Volleyball Players," International Journal of Human Movement and Sports Sciences, Vol. 9, No. 2, pp. 334 - 339, 2021. DOI: 10.13189/saj.2021.090222.

(b): Nur Cholis Majid, Fauzi (2021). The Effect of Sprint Training on Vertical Jump Height of Female Youth Volleyball Players. International Journal of Human Movement and Sports Sciences, 9(2), 334 - 339. DOI: 10.13189/saj.2021.090222.

Copyright $\odot 2021$ by authors, all rights reserved. Authors agree that this article remains permanently open access under the terms of the Creative Commons Attribution License 4.0 International License

\begin{abstract}
The aim of this study was to investigate the effect of the $60-\mathrm{m}$ sprint training program on the vertical jump height of female youth volleyball players. In this quasi-experimental study, a one-group pretest/posttest design was utilized. Participants were 10 female youth volleyball players (aged 12-15) who were registered in a 12-session sprint training program at a junior sports organization in Yogyakarta, Indonesia. The training program was carried out on a $100-\mathrm{m}$ flat track at the Athletic Field, Faculty of Sport Sciences of Yogyakarta State University. The stand and reach method was used to measure the vertical jump height. To compare the pretest and posttest scores, a paired samples $t$-test was used. The results indicated that there was a significant increase in vertical jump height from pretest to posttest with a high effect size. Thus, it can be concluded that a 4-week sprint training program can effectively increase the vertical jump height of young volleyball players. It is recommended that volleyball coaches and trainers implement a sprint training program as a step towards developing the vertical jump of their young athletes.
\end{abstract}

Keywords Sprint Training Program, Vertical Jump Height, Young Volleyball Players

\section{Introduction}

Volleyball is one of the most popular team sports in the world. The characteristics of this sport are short and explosive movement patterns, agile and fast positioning, jumps, and blocks [1]. Volleyball is one of the most practiced sports in the world where smash is called the main attack action which is closely related to the outcome of the match [2,3]. A volleyball athlete does not only need good basic playing techniques, but they also have to do physical training to maintain their fitness. The physical components needed in volleyball are speed, agility, upper-body, and lower-body muscular power, and maximal aerobic power [4]. The power of the arm and leg muscles, in particular, plays an important role in supporting spiking skills — one of the vital skills needed to be a good offensive volleyball player.

Kumar et al. [5] revealed that the characteristic of volleyball is that it requires the players to jump. Agopyan et al. [6] in a study also suggested that volleyball players have a high vertical jump. This means that each player must have strong power to jump as provisions for hitting, blocking, and serving. For example, a high jumping ability is required when a volleyball player has to smash. In addition, high jumps when blocking will also make it easier for the team to defend. This clearly shows that volleyball players need a large explosive power in the extremities when they need to make jumps and punches with high speed [7]. High jumps can be achieved if the muscle power in the legs has been trained with bails. Leg muscle power is related to the ability of an athlete to exert maximum strength and speed in the shortest possible time [8]. Jump height in other words can be achieved when a volleyball player performs exercises related to power or explosive power. 
Power is theoretically explained as the product of speed and power [8]. The jump height can be increased by training the speed at which the leg muscles contract. It is stated in the literature that the method often used to increase athletes' jump height is the plyometric method $[9,10]$. However, on the other hand, previous studies reported that this type of training has the potential to cause injury to the vertebrae, osteoarticular, acute muscle soreness, and muscle damage [11-14]. Miller et al. [15] revealed that greater intensity in plyometric training is considered capable of increasing strength production in the musculoskeletal system and can result in the occurrence of the pain of delayed-onset muscle soreness. Thus, the researchers conducted a way to minimize injury while improving the performance of young volleyball athletes by utilizing other training programs. In order to increase the contraction speed of the leg muscles, the current study used sprint training.

Sprint is an essential component in many sports, particularly volleyball. Sprinting is an explosive movement that can lead to an increase in human muscle strength and is usually used as a testing exercise, both for individual and team sports [16]. Sprint workouts can be done on a gentle slope or downhill. It is intended that the muscles contract quickly to move, so that the speed of muscle contraction will increase. In short, sprinting can be an effective training method for the development of leg extensor strength and power [16]. Training programs also benefit the physical and physiological development of volleyball players [17]. Kaynak et al. [18] explored the effect of 20-m repeated sprint training on the aerobic capacity of college volleyball players and found that the addition of repeated sprint training programs was successful in increasing aerobic capacity and anaerobic performance. In addition, Erylmaz et al. [19] showed that repeated sprint training can increase the isocapnic buffering phase of volleyball players, indicating that sprint training is very useful in volleyball.

The aim of the exercise is to improve the athlete's ability to prepare for a match $[20,21]$. It is clear that players perform various types of physical activity such as sprints and jumps in volleyball matches [18]. However, to our knowledge, studies evaluating the effect of a sprint training program on vertical jump height among novice volleyball athletes have not been explored. Therefore, this study aims to evaluate the effects of 4-week sprint training on vertical jump height. We hypothesized that a sprint training program would increase the vertical jump height of beginner volleyball athletes. Through this training program, we hope that the training program will be more efficient and effective and prevent athletes from injury.

\section{Materials and Methods}

\subsection{Research Design}

The purpose of this study was to determine whether the 60-m sprint training program could provide a greater increase in vertical jumps among young female volleyball players. In this quasi-experimental study, a one-group pretest/posttest design was employed. A quasi-experimental design is suitable for building cause-and-effect relationships [22]. Pretest and posttests were carried out 2 days before and after the training period where this process was assessed by the same researchers. We decided on a 4-week training period without interrupting the start of the season.

\subsection{Participants}

A total of 10 female youth volleyball players were registered in a 4-week sprint training program at a junior sports organization in Yogyakarta, Indonesia. They attend the entire program and complete the pretest and posttest. All of these participants were between 12-15 years old (see Table 1). Of note, all participants had no history of injury and chronic illness. They start and finish a training program without injury and illness. Subjects were also instructed not to take any dietary supplements during the study. As ethical considerations, all athletes provided written informed consent to researchers prior to volunteering. Before the data collection, the institutional review board has also been approved in this study.

Table 1. Physical characteristics of the participants

\begin{tabular}{ccc}
\hline Age $(\mathrm{y})$ & Height $(\mathrm{cm})$ & Weight $(\mathrm{kg})$ \\
\hline $13.449 \pm 0.935$ & $161.000 \pm 4.346$ & $54.100 \pm 9.960$ \\
\hline
\end{tabular}

\subsection{Training Protocols}

There were 12 training sessions (30 minutes per session) over the 4-week training program. All participants were assigned to sprint training. Training sessions were scheduled for 3 days per week (i.e., Monday, Wednesday, and Friday at $4-5 \mathrm{pm})$. The training program was carried out on a 100-m flat track at the Athletic Field, Faculty of Sport Sciences of Yogyakarta State University, Indonesia. The researchers instructed athletes not to do physical exercise outside the set program and they were instructed to continue their usual eating habits during the study.

The training session began with a 5-minute static warm-up led by an athlete to prevent injury. This was followed by a 10-minute happy dynamic warm-up aimed at preparing the muscles for the workout. Colling down was then carried out for 10 minutes to stretch muscles and joints after the training program, accompanied by adjusting the breath so that the heart rate returns to normal.

The researchers were 1 meter beside the starting line and the research assistant was exactly 1 meter beside the finish line. The researchers blew the whistle and the other researchers recorded the time of the sprint. The $60-\mathrm{m}$ sprint in this study was carried out in 3 sets with 5 
repetitions in each set. Each participant was given time to perform a recovery of 75 seconds between each repetition with the time lag between sets being 150 seconds. The required time from start to finish should be less than 15 seconds.

\subsection{Vertical Jump Assessment}

The stand and reach method was used by researchers to measure vertical jump height [23]. All participants were instructed to first apply lime powder or magnesium carbonate to the tips of their fingers before performing the vertical jump. The initial reach height was determined by asking participants to stand upright against a wall, feet together with the scale board on their left or right. Then the hand that was near the wall was raised straight up and the palm was attached to the scale board to leave a mark. Next, each participant will start with the preferred knee and arm or arms bent and raised in a vertical position while the other arm hangs at his side. All participants were not allowed to swing their arms to help with the momentum of the jump. The next movement was for participants to jump as high as possible while tapping the board with their fingertips, leaving a mark. The boards were designed with a height from 150 to $350 \mathrm{~cm}$. Each participant was allowed to perform two to three jumps in which the highest jump successfully made will be used for data analysis. Each participant was allowed to make 3 test jumps with a 30 -second recovery between each jump.

\subsection{Statistical Analysis}

Descriptive statistics in this study included the mean and standard deviation. The normality test was performed using the Shapiro-Wilk, while the homogeneity test was carried out using the Levene test. After fulfilling the assumption test $(p>0.05)$, a paired-samples $t$-test was then used to compare the pretest and posttest scores. A calculation was performed on Cohen's $d$ [24] to show how much increase on the pretest to posttest scores were. In addition, the effect size classification for strength training was adapted: $<0.35$ indicates a trivial effect; $0.35-0.80$ for small effect; $0.80-1.50$ for medium effect; and $>1.50$ for large effect [25]. Finally, all data were analyzed using SPSS version 17 (SPSS Inc., USA) at a significance level of 0.05 .

\section{Results}

The jump heights were assessed before and after the training period are presented in Table 2. The results obtained indicate a significant increase in vertical jump height from pretest $(34.200 \pm 2.616)$ to posttest $(37.000 \pm$ 2.667). In sum, after a 4 -week period, it appears that the sprint training program was successful in increasing the athletes' vertical jump by an additional $2.80 \mathrm{~cm}$.

Table 2. Assessment of Vertical Jump Height after 4 Weeks

\begin{tabular}{cccccc}
\hline & $N$ & Min & Max & $M$ & $S D$ \\
\hline Pretest & 10 & 31.00 & 39.00 & 34.200 & 2.616 \\
Posttest & 10 & 33.00 & 42.00 & 37.000 & 2.667 \\
\hline
\end{tabular}

In order to prove the increase in vertical jump height before and after the training program, the researchers conducted a paired samples $t$-test. The analysis results are presented in Table 3.

There is a significant increase found in vertical jump heights at pretest and posttest based on the results of the t-test after participants attended a training program with a high effect size $(d=3.05)$ (see Table 3$)$. Comparison between vertical jumps at the pretest and the scores obtained after 4 weeks revealed that the sprint training program increased the athletes' vertical jumps by $8.19 \%$ (paired differences; $2.800 \pm 0.919, p<0.05$ ). Thus, the sprint training program can be concluded that it will effectively increase the vertical jump height of beginner volleyball athletes.

Table 3. T-Test Results for Vertical Jump Height before and after the Training Program

\begin{tabular}{|c|c|c|c|c|c|c|c|c|c|}
\hline \multicolumn{2}{|c|}{ Pretest } & \multicolumn{2}{|c|}{ Posttest } & \multicolumn{2}{|c|}{ Paired Differences } & \multirow{2}{*}{$t$} & \multirow{2}{*}{$d f$} & \multirow{2}{*}{$p$} & \multirow{2}{*}{ Cohen's $d$} \\
\hline$M$ & $S D$ & $M$ & $S D$ & $M$ & $S D$ & & & & \\
\hline 34.200 & 2.616 & 37.000 & 2.667 & 2.800 & 0.919 & -9.635 & 9 & 0.000 & 3.05 \\
\hline
\end{tabular}

*Significantly different at $p<0.05$. 


\section{Discussion}

Current research has successfully evaluated the effect of sprint training on vertical jump height of 12-15 years old youth volleyball players. It was found that there was a significant effect of speed training on the jump height of beginner volleyball athletes based on the findings obtained. The percentage increase in vertical jump height is $2.80 \mathrm{~cm}$ with a height effect size. Our study results show that the percentage increase in the sprint increased vertical jump heights training program is $8.19 \%$. It may be argued that the training protocol used in the current study was capable of producing a significant increase in the vertical jump, particularly for younger female athletes.

Our research strengthens the findings of previous studies. Kotzamanidis [26] in a study found that the 10 -week sprint training program was successful in increasing vertical jump height significantly. Similar to our results, Kotzamanidou et al. [27] reported that vertical jumps increased after five weeks of training for sprinting. Tønnessen et al. [28] reported that repeated 40-m sprints training had a positive effect on vertical jump performance. Similarly, Bonnette et al. [29] also found that the 4-week sprint training program had positive results on vertical jumps. In fact, Markovic et al. [16] suggested sprint training as a training method that could be applied to increase the explosive performance of athletes.

We argue that every athlete needs strong leg power to produce high jumps. It is expected that their power can increase with the increase in the athlete's sprint speed during training since power is influenced by strength and speed. As stated by Markovic et al. [16], sprint training has been shown to improve leg extensor strength, power, and agility performance. This can partly be explained by the fact that sprinting is able to activate most of the leg muscles. In a study, Saudini and Sulistyorini [30] stated that muscular power is a person's ability to use the maximum strength that is exerted in the shortest possible time. Power can briefly be described as a combination of strength and speed or the exertion of maximum muscle force with maximum speed as it is well known that this power can be increased through training. Thus, we believe that the sprint training program provided will be beneficial in increasing vertical jump height, as reported by Markovic et al. [16].

Training is a systematic process to improve athletes' abilities to the maximum level [31]. A regular, disciplined, directed and sustainable exercise program is considered capable of increasing physical work both psychologically and physiologically. Movements performed during repeated exercises will result in the formation of conditional reflexes, learning to move, and memorizing movements [32]. In the end, through repeated speed training, the athletes' running speed will increase so that the leg power will eventually increase. This is in accordance with the opinion of Bompa and Haff [8] who claim that the training provided regularly can help the body adapt to the training given. Tønnessen et al. [28] reinforce previous findings and inform that speed endurance training can have a positive effect on athletes' leaping power. Kotzamanidou et al. [27] also assumed that sprint performance led to the adaptation to the muscle tendons complex. In fact, Markovic et al. [16] concluded that sprint training produced a greater training effect on muscle function and athletic performance than conventional plyometric training. Furthermore, Mero et al. [33] agree that sprint training can lead to increased muscle power capabilities. These findings prove that this fact can explain the effect of running the sprint on the vertical jump in the current study.

\section{Conclusions and Suggestions}

In conclusion, the findings based on the results of this study are that there is a significant mean difference for the vertical jump between the pretest and posttest. In other words, the present study provides evidence that the 4-week sprint training program can produce significant increases in vertical jump among young female volleyball players. Thus it can be suggested to volleyball coaches and trainers that they need to implement a sprint training program as a way to develop their athletes' vertical jump. However, there are some limitations in this study even though the findings are statistically significant. Given that the current study involved a limited sample, it is suggested that future studies should include a larger sample, more precisely not just young female volleyball athletes. It is recommended for future research to compare the impact of sprint and plyometric training programs on improving vertical jumping abilities (e.g., drop jumps, countermovement jumps, and squat jump performances) and agility in women's volleyball athletes. In addition, it was found that it was important to compare the effects of a sprint training program with varying intensities and durations on different athletic populations [34]. Current research has only been able to show the effects of short-term training (4 weeks), so research on the long-term effects of a sprint training program should be carried out in the future.

\section{REFERENCES}

[1] Sattler T., Hadzic V., Dervisevic E., Markovic G., "Vertical jump performance of professional male and female volleyball players: Effects of playing position and competition level," Journal of Strength and Conditioning Research, vol. 29, no. 6, pp. 1486-1493, 2015. DOI: 10.1519/JSC.0000000000000781 
[2] Oliveira L. S., Moura T. B. M. A., Rodacki A. L. F., Tilp M., Okazaki V. H. A., "A systematic review of volleyball spike kinematics: Implications for practice and research," International Journal of Sports Science \& Coaching, vol. 15, no. 2, pp. 239-255, 2020. DOI: 10.1177/1747954119899881

[3] Challoumas D., Artemiou A., "Predictors of attack performance in high-level male volleyball players. International Journal of Sports Physiology and Performance, vol. 13, no. 9, pp. 1230-1236, 2018. DOI: 10.1123/ijspp.2018-0125

[4] Gjinovci B., Idrizovic B., Uljevic O., Sekulic D., "Plyometric training improves sprinting, jumping and throwing capacities of high level female volleyball players better than skill-based conditioning," Journal of Sports Science and Medicine, vol. 16, no. 4, pp. 527-535, 2017. https://www.ncbi.nlm.nih.gov/pmc/articles/PMC5721183/

[5] Kumar S., Goswami J., Kumar A., "Effect of training program on volleyball skills of inter-university level volleyball players," International Journal of Movement Education and Sports Sciences, vol. 4, no. 1, pp. 21-25, 2016.

[6] Agopyan A., Ozbar N., Ozdemir S. N., "Effects of 8-week thera-band training on spike speed, jump height and speed of upper limb performance of young female volleyball players," International Journal of Applied Exercise Physiology, vol. 7, no. 1, pp. 64-76, 2018. DOI: 10.22631/ijaep.v7i1.218

[7] Mannan M. S., Johnson D. P., "Impact of volleyball specific plyometric training on arm and leg explosive power of male volleyball players," Asian Journal of Applied Research, vol. 1, no. 2, pp. 28-32, 2015. http://apjournals.org/images/issue s/201.pdf

[8] Bompa T. O., Haff G., "Periodization theory and methodology of training", Sheridan Books, 2019.

[9] Ramirez-Campillo R., Andrade D. C., Nikolaidis P. T., Moran J., Clemente F. M., Chaabene H., Comfort P., "Effects of plyometric jump training on vertical jump height of volleyball players: A systematic review with meta-analysis of randomized-controlled trial," Journal of Sports Science and Medicine, vol. 19, no. 3, pp. 489-499, 2020.

https://www.ncbi.nlm.nih.gov/pmc/articles/PMC7429440/

[10] Stojanović E., Ristić V., McMaster D. T., Milanović Z., "Effect of plyometric training on vertical jump performance in female athletes: A systematic review and meta-analysis," Sports Medicine, vol. 47, no. 5, pp. 975-986, 2016. DOI: 10.1007/s40279-016-0634-6

[11] Almeida S. A., Williams K. M., Shaffer R. A., Brodine S. K., "Epidemiological patterns of musculoskeletal injuries physical training," Medicine \& Science in Sports \& Exercise, vol. 31, no. 8, pp. 1176-1182, 1999. DOI: 10.1097/00005768-199908000-00015

[12] Arazi H., Asadi A., "The effect of aquatic and land plyometric training on strength, sprint, and balance in young basketball players," Journal of Human Sport and Exercise, vol. 6, no. 1, pp. 101-111, 2011.

[13] Grantham N., "Plyometrics and sports injures-spinal shrinkage, patellar tendinitis, lower limbs injuries, heel-pad bruising, shin splints and stress fractures," Sports Injury Bulletin, 2006.
[14] Jamurtas A. Z., Fatouros L. G., Buckenmeyer P., Kikkjnidis, E, Tazildaris K., Kambas A., Kyriazis G., "Effects of plyometric exercise on muscle soreness and plasma creatine kinase levels and its comparison with eccentric and concentric exercise," Journal of Strength and Conditioning Research, vol. 14, no. 1, pp. 68-74, 2000. https://journals.lww.com/nsca-jscr/Abstract/2000/02000/Eff ects_of_Plyometric_Exercise_on_Muscle_Soreness.12.aspx

[15] Miller M. G., Berry D. C., Bullard S., Gilders R., "Comparisons of land-based and aquatic-based plyometric programs during an 8-week training period," Journal of Sport Rehabilitation, vol. 11, no. 4, pp. 268-283, 2002. DOI: $10.1123 /$ jsr.11.4.268

[16] Markovic G., Jukic I., Milanovic D., Metikos D., "Effects of sprint and plyometric training on muscle function and athletic performance," Journal of Strength and Conditioning Research, vol. 21, no. 2, pp. 543-549. DOI: 10.1519/R-19535.1

[17] Lidor R., Gal Z., "Physical characteristics and physiological attributes of adolescent volleyball players: A review," Pediatric Exercise Science, vol. 22, no. 1, pp. 114-134, 2010. DOI: $10.1123 /$ pes.22.1.114

[18] Kaynak K., Eryılmaz S. K., Aydoğan S., Mihailov D., "The effects of 20-m repeated sprint training on aerobic capacity in college volleyball players," Biomedical Human Kinetics, vol. 9, no. 1, pp. 43-50, 2017. DOI: 10.1515/bhk-2017-0007

[19] Erylmaz S., Kaynak K., Polat M., Aydogan S., "Effects of repeated sprint training on isocapnic buffering phase in volleyball players," Revista Brasileira de Medicina do Esporte, vol. 24, no. 4, pp. 286-290, 2018. DOI: $10.1590 / 1517-869220182404185842$

[20] Cooney G., Dwan K., Mead G., "Exercise for depression," Journal of the American Medical Association, vol. 311, no. 23, p. CD004366, 2014. DOI: 10.1002/14651858.CD00436 6.pub6

[21] Garber C. E., Blissmer B., Deschenes M. R., Franklin B. A., Lamonte M. J., Lee I. M., Swain D. P., "Quantity and quality of exercise for developing and maintaining cardiorespiratory, musculoskeletal, and neuromotor fitness in apparently healthy adults: Guidance for prescribing exercise," Medicine and Science in Sports and Exercise, vol. 43, no. 7, pp. 1334-1359, 2011. DOI: 10.1249/MSS.0b013e318213fefb

[22] Page P., "Research designs in sports physical therapy," International Journal of Sports Physical Therapy, vol. 7, no. 5, pp. 482-492, 2012.https://www.ncbi.nlm.nih.gov/pmc/ar ticles/PMC3474303/

[23] Baechle T. R, Earle R. W., "Essentials of strength training and conditioning, 2nd ed, Human Kinetics, 2000.

[24] Cohen J., "A power primer," Psychological Bulletin, vol. 112, no. 1, pp. 155-159, 1992. DOI: 10.1037//0033-2909.1 12.1.155

[25] Rhea M. R., "Determining the magnitude of treatment effects in strength training research through the use of the effect size," Journal of Strength and Conditioning Research, vol. 18, no. 4, pp. 918-920, 2004. DOI: 10.1519/14403.1

[26] Kotzamanidis C., "The effect of sprint training on running performance and vertical jumping in pre-adolescent boys," Journal of Human Movement Studies, vol. 44, no. 3, pp. 225-240, 2003. 
[27] Kotzamanidou M., Tsiadimas C., Michailidis I., Bassa E., Chatzopoulos D., Gerodimos C., Kotzamanidis C., "The effect of a five week training intervention program of sprint and jumping exercises on running velocity and vertical jump performance, in prepubertal boys," International Journal of Performance Analysis in Sport, vol. 5, no. 1, pp. 22-30, 2005. DOI: $10.1080 / 24748668.2005 .11868312$

[28] Tønnessen E., Shalfawi S. A., Haugen T., Enoksen E., "The effect of 40-m repeated sprint training on maximum sprinting speed, repeated sprint speed endurance, vertical jump, and aerobic capacity in young elite male soccer players," Journal of Strength and Conditioning Research, vol. 25, no. 9, pp. 2364-2370, 2011. DOI: 10.1519/JSC.0b013e3182023a65

[29] Bonnette R., Spaniol F., Melrose D., Ocker L., Dyer R., "The effect of agility, plyometric, and sprint training on the speed, endurance and power of high school soccer players," Journal of Strength and Conditioning Research, vol. 25, p. S119, 2011. DOI: 10.1097/01.JSC.0000395770.58697.94

[30] Saudini A. F., Sulistyorini S., "Pengaruh latihan squat terhadap peningkatan power otot tungkai [Effect of squat training on increasing leg muscle power]" Indonesia Performance Journal, vol. 1, no. 2, pp. 71-75, 2017. http://journal2.um.ac.id/index.php/jko/article/view/2453

[31] Alim S., Kawabata M., Nakazawa M., "Evaluation of disaster preparedness training and disaster drill for nursing students," Nurse Education Today, vol. 35, no. 1, pp. 25-31, 2015. DOI: 10.1016/j.nedt.2014.04.016

[32] Nala G. N., "Prinsip pelatihan fisik olahraga [The principles of sports physical training]", Komite Olahraga Nasional Indonesia Daerah Bali, 2011.

[33] Mero A., Komi P. V., Gregor R. J., "Biomechanics of sprint running. A review," Sports Medicine, vol. 13, no. 6, pp. 376-392, 1992. DOI: 10.2165/00007256-199213060-00002

[34] Brian D., Declan B., Dan H. "The relationship of aerobic endurance and linear speed on repeat sprint ability performance in female international footballers," International Journal of Human Movement and Sports Sciences, vol. 8, no. 4, pp. 147 - 153, 2020. DOI: 10.13189/saj.2020.080407. 